\title{
FSH increases the different LH- and hCG-dependent intracellular signalling and the downstream life/death signals in vitro
}

\author{
Livio Casarini ${ }^{1,2}$, Laura Riccetti ${ }^{1}$, Francesco De Pascali ${ }^{1}$, Alessia Nicoli ${ }^{3}$, Simonetta Tagliavini ${ }^{4}$, \\ Tommaso Trenti ${ }^{4}$, Giovanni Battista La Sala ${ }^{3,5}$, Manuela Simoni ${ }^{1,2,6}$
}

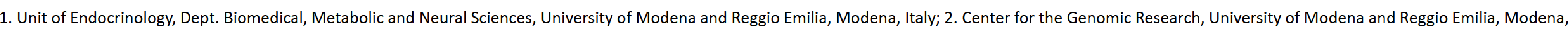

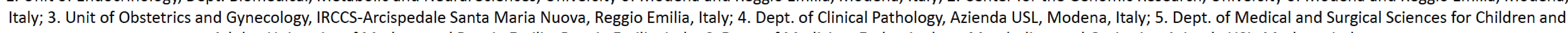
Adults, University of Modena and Reggio Emilia, Reggio Emilia, Italy; 6. Dept. of Medicine, Endocrinology, Metabolism and Geriatrics, Azienda USL, Modena, Italy

\section{Introduction}

Luteinizing hormone (LH) and choriogonadotropin (hCG) are glycoprotein hormones regulating ovarian function and pregnancy. They were equivalently used in assisted reproduction techniques (ART) due to their binding to a common receptor (LHCGR). However, differences between $\mathrm{LH}$ and hCG were demonstrated at molecular and physiological level [1]. Our previous study revealed that LHCGR mediates hCG-dependent steroidogenesis-related signaling and LH-dependent proliferative and antiapoptotic events in human granulosa cells [2].

\section{Aim}

The aim of this study is to evaluate how follicle-stimulating hormone (FSH) co-treatment, in the ART therapeutic doserange, affects the different $\mathrm{LH}$ - and $\mathrm{hCG}$-specific responses in vitro.

\section{Study design}

We evaluated phospho-CREB, -ERK1/2 and -AKT activation by Western blotting, gene expression by real-time PCR, cAMP, progesterone and estradiol production by ELISA, and cell viability by MTT assay in human granulosa-lutein cells (hGLC). LH and hCG dose-response experiments (0.1 pM$1.0 \mathrm{nM}$ range) were performed, in the presence of $10 \mathrm{nM}$ FSH.

\section{Results}

In the presence of FSH, hCG biopotency is higher than that of $\mathrm{LH}$, and is about 5 -fold increased, in terms of cAMP activation (fig.1), compared to previous data obtained in the absence of FSH [2]. Moreover, different LH and hCG dose-response curves were observed, in terms of $50 \%$ effective doses (EC50s), hill-slopes and maximal levels (Mann-Whitney's $U$-test; $\quad \mathrm{p}<0.05 ; \mathrm{n}=6$ ), suggesting hormone-specific receptor cooperativity and biopotency. In the presence of FSH, the range of effective hCG doses increased, in terms of CREB phosphorylation (fig.2). FSH increased the LH-dependent ERK1/2 and AKT phosphorylation, the expression of the $X$-linked inhibitor of apoptosis (XIAP) gene (fig.3), and the cell viability (MannWhitney's $U$-test; $p<0.05 ; n=4)$, resulting in anti-apoptotic effects (fig.4). Consistently with the effect on CAMP and pCREB activation, steroid production increased under hCG and FSH co-treatment (figs.5, 6).

\section{Discussion}

FSH potentiates the LH-dependent anti-apoptotic and the hCG steroidogenic (and pro-apoptotic) potential in vitro. The different modulatory activity of FSH on LH and hCG action in vitro reflects their different physiological functions, consisting in proliferative effects exerted by LH during the follicular phase and before trophoblast development, and the high steroidogenic potential of hCG requested to sustain pregnancy. These findings were recently published [3].

\section{References}

1. Grzesik et al. Front Endocrinol (Lausanne). 2015. 6:140; 2. Casarini et al. PLoS One. 2012. 7(10); 3. Casarini et al. Mol Cell Endocrinol. 2016. 422:103-14.

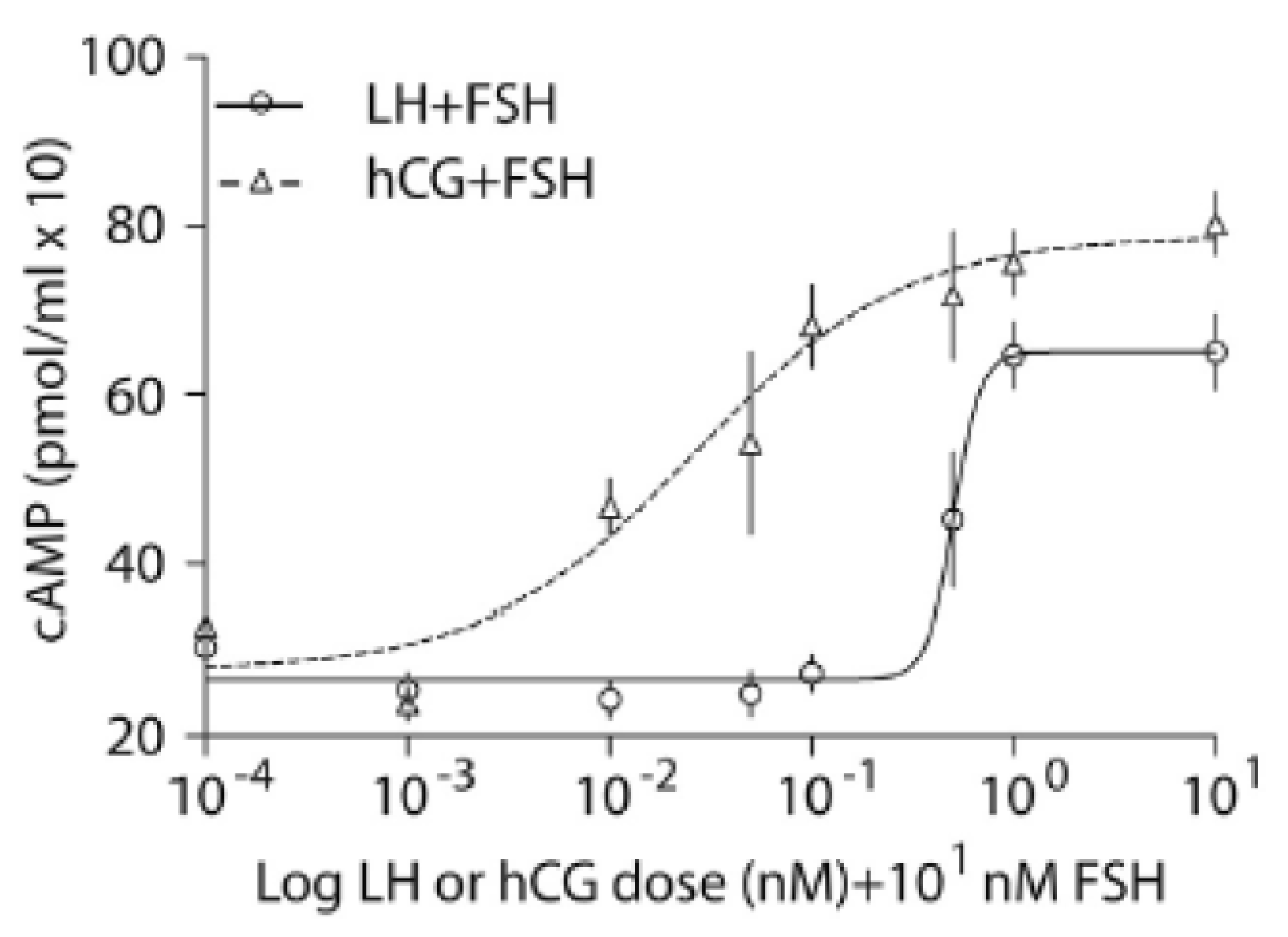

Figure 1. cAMP dose-response to $\mathrm{LH}$ and $\mathrm{hCG}$, in the presence of $10 \mathrm{nM}$ FSH treatment. $\mathrm{hGLC}$ were stimulated $2 \mathrm{~h}$ by $0-1 \times 10^{1} \mathrm{nM} \mathrm{LH}$ or $\mathrm{hCG}$ together with the fixed FSH dose, in the presence of IBMX, then CAMP was measured by ELISA. CAMP levels were extrapolated by a standard curve and expressed as $\mathrm{pmol} / \mathrm{ml}$. All the results are represented as means $\pm \mathrm{SD}(\mathrm{n}=6)$ in a logarithmic $X$ axis, then non-linear regressions were plotted. The EC50 $(\mathrm{LH}+\mathrm{FSH}=440.9 \pm 271.4$ vs $\mathrm{hCG}+\mathrm{FSH}=20.3 \pm 1.2 ; \mathrm{p}=0.0006)$, H-slope $(\mathrm{LH}+\mathrm{FSH}=2.9 \pm 1.0$ vs $\mathrm{hCG}+\mathrm{FSH}=1.0 \pm 0.2 ; \mathrm{p}=0.0023)$ and maximal $\mathrm{cAMP}$ values $(\mathrm{LH}+\mathrm{FSH}=650.3 \pm 97.8$ vs $\mathrm{hCG}+\mathrm{FSH}=795.4 \pm 46.10 ; \mathrm{p}=0.0175)$ were compared by Mann-Whitney's U-test.

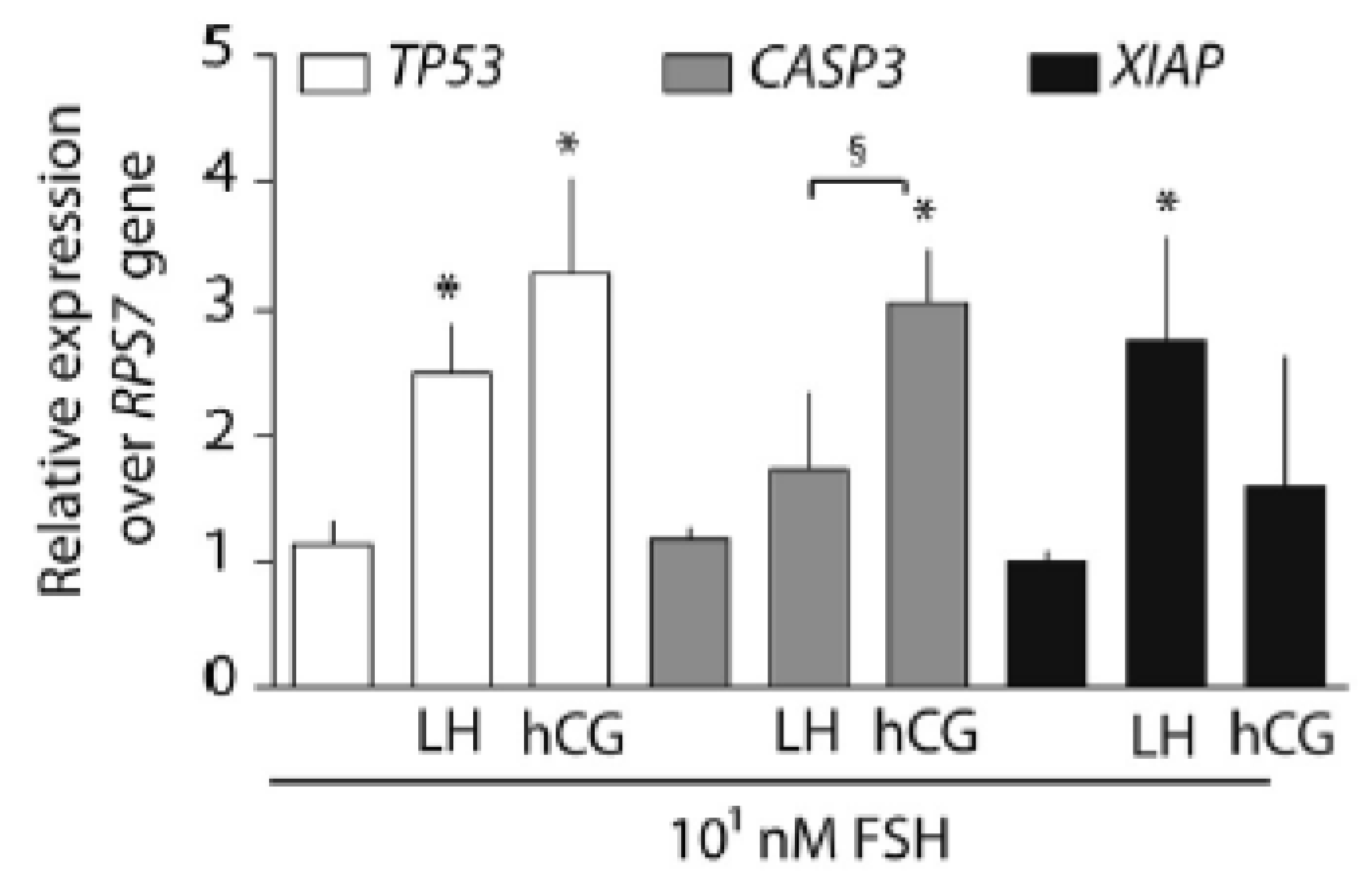

Figure 3. Gene expression analysis. The expression of target genes regulating pro- and anti-apoptotic events was evaluated in $2-\mathrm{h} 1 \times 10^{-1} \mathrm{nM}$ LH- or hCGstimulated $\mathrm{hGLC}$, in the presence of $1 \times 10^{1} \mathrm{nM} \mathrm{FSH}$, after $12 \mathrm{~h}$, by real time PCR. Controls were prepared by incubating the cells in media without LH or hCG. Each value was normalized by the RPS7 control gene expression and graphically represented as fold increase over unstimulated controls in relative units scale ( $n=4$; means $\pm S D$ ). Legend: TP53 gene encoding the tumor protein
53 (P53); CASP3 gene encoding the procaspase 3 protein; XIAP gene encoding the $X$-linked inhibitor of apoptosis factor protein. ${ }^{*}=$ statistically significant the X-linked inhibitor of apoptosis factor protein. ${ }^{*}=$ statistically significant
difference versus FSH alone (basal); $\S=$ statistically significant difference between LH- and hCG-stimulated cells (ManneWhitney's U-test; $p<0.05 ; n=4$ ).

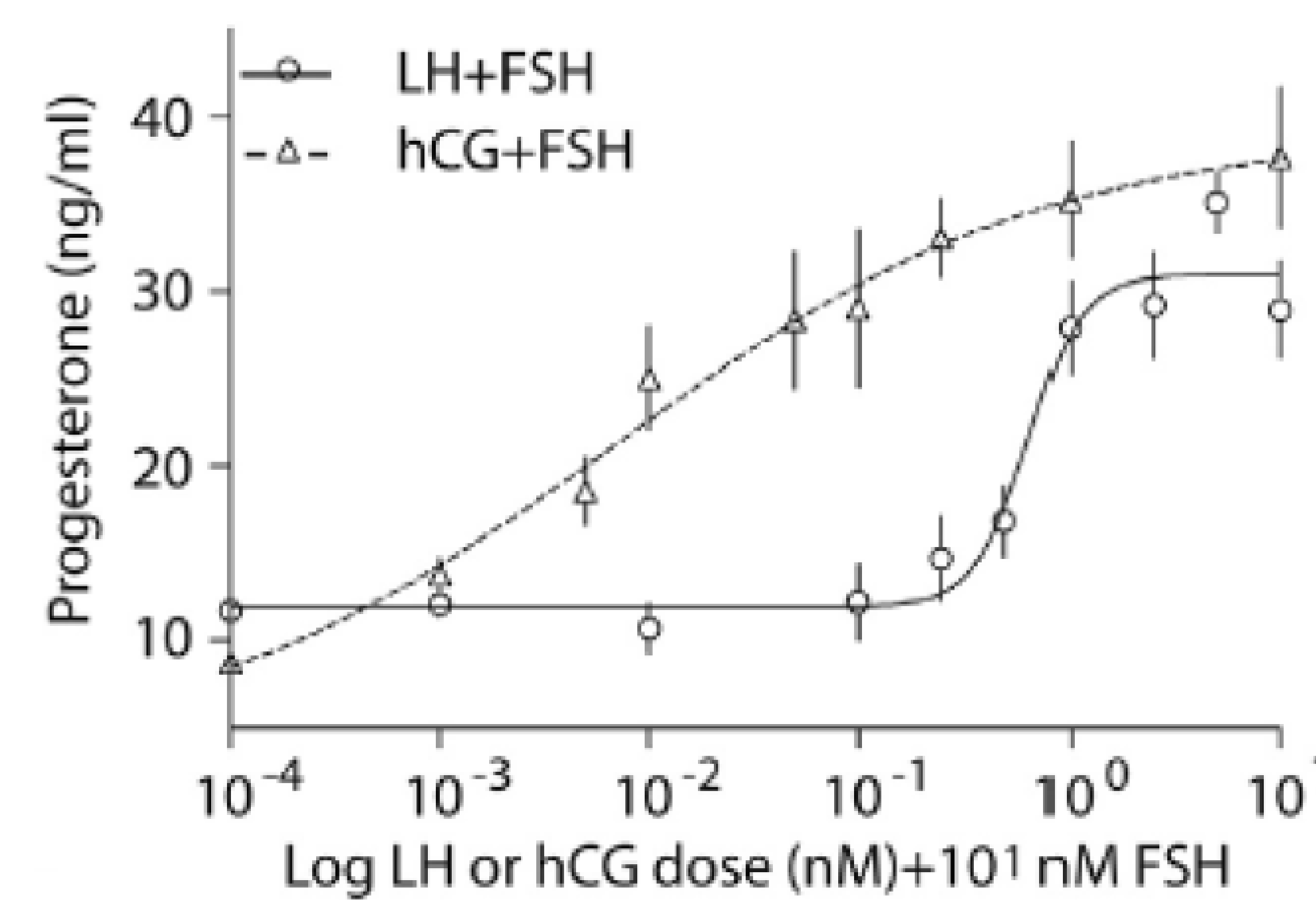

Figure 5. Progesterone dose-response in hGLC upon 2-h stimulation by increasing LH or hCG doses, together with $1 \times 10^{1} \mathrm{nM}$ FSH. Progesterone was measured by ELISA after $24 \mathrm{~h}$ then, hormone levels expressed as $\mathrm{ng} / \mathrm{ml}$ in the graph using a logarithmic $X$-axis (means $\pm S D ; n=6)$. Non-linear regressions
were calculate and the $E C 50(L H+F S H=671.2 \pm 240.6$ vs $h C G+F S H=82.7 \pm 46.8 ;$ were calculate and the $E C 50(L H+F S H=671.2 \pm 240.6$ vs $h C G+F S H=82.7 \pm 46.8$; maximal progesterone levels $(\mathrm{LH}+\mathrm{FSH}=35.0 \pm 2.11$ vs $\mathrm{hCG}+\mathrm{FSH}=39.0 \pm 3.4$; $\mathrm{p}=0.3939$ ) were extracted from the curves and compared by Mann-Whitney's U-test.

\section{Winner of ESE Basic Science Meeting Grant}

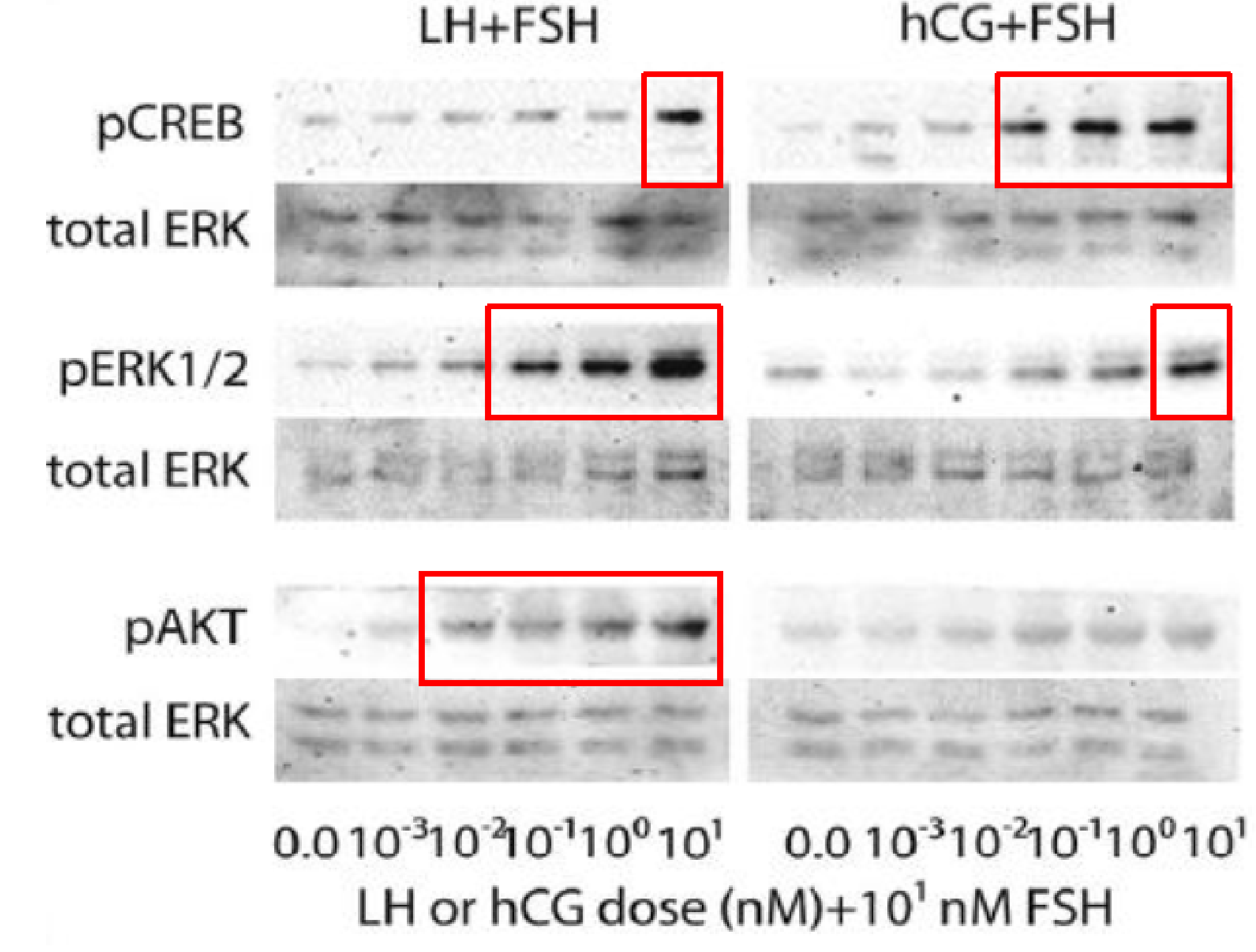

Figure 2. Phosphorylation of CREB, ERK1/2 and AKT induced by increasing LH hCG concentrations, in the presence of a fixed FSH dose. hGLC were imulated 15 min by $0-1 \times 10^{1} \mathrm{nM} \mathrm{LH}$ or hCG together with $1 \times 10^{1} \mathrm{nM}$ FSH, then the signaling pathways activation was qualitatively evaluated by Western blotting using specific antibodies (image representative of 4 experiments). Total ERK served as normalizer. The signals detected by Western blotting were semiquantitatively evaluated to be represented as means \pm SD and used used for statistical analysis after background subtraction. Red squares indicates significant differences versus $\mathrm{LH}$ - or hCG-unstimulated (basals) (MannWhitney's U-test; $p<0.05 ; n=4$ ).

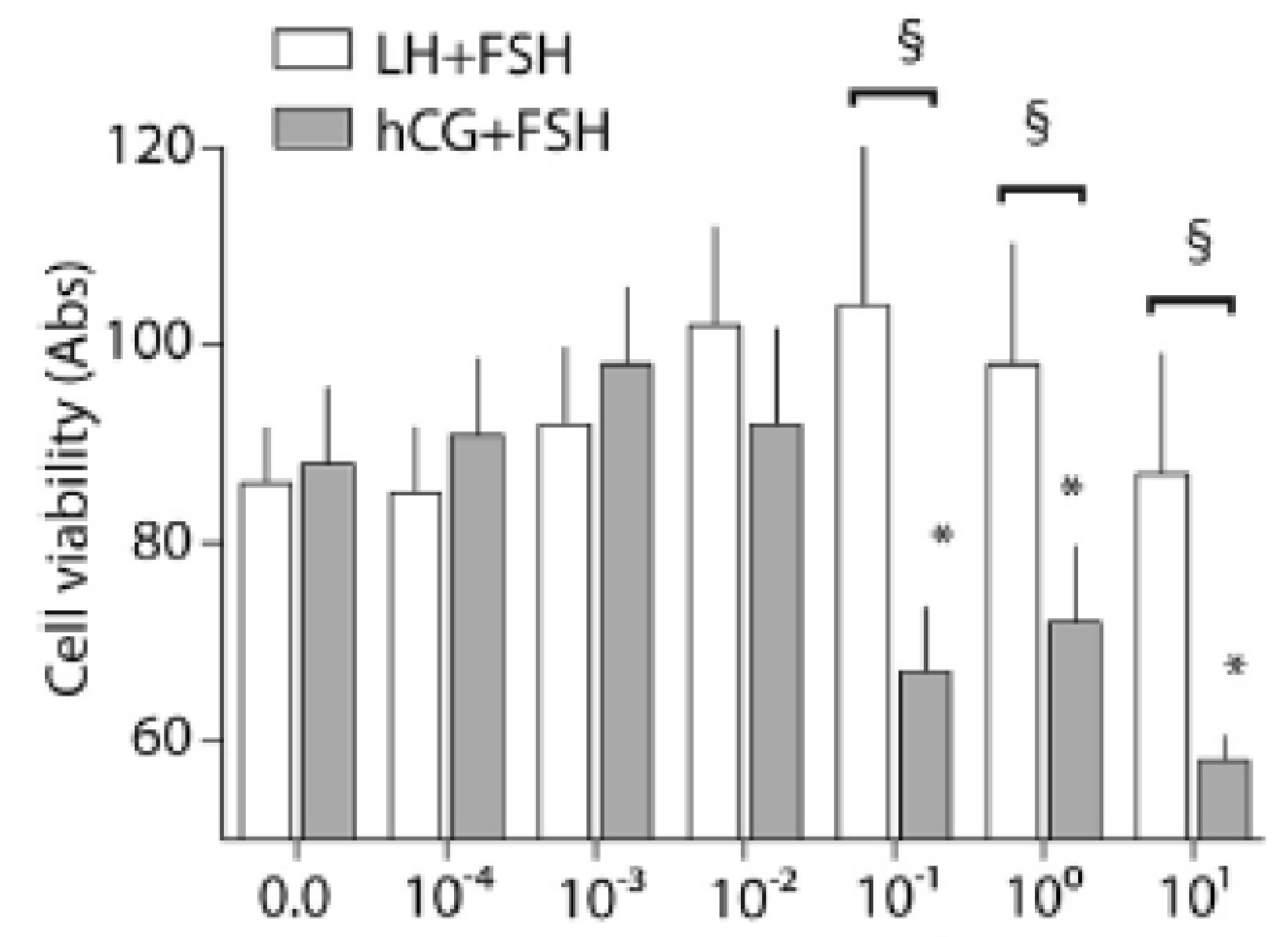

LH or hCG dose $(\mathrm{nM})+10^{1} \mathrm{nM}$ FSH

Figure 4. Cell viability assay in hGLC stimulated by different LH or hCG doses, in the presence of $1 \times 10^{1} \mathrm{nM}$ FSH. The cells were treated using the short-term thimulation protocol, then they were washed twice. The cell viability was assessed after 2 days by MTT assay and measured as absorbance using a spectrophotometer. The results were graphically represented as means $I S D$ fter background subtraction * ${ }^{*}=$ statistically significant difference versus FSH (basal); $\S=$ statistically significant difference between LH+hCG- and LH+FSHstimulated cells (Mann-Whitney's U-test; $p<0.05 ; n=4$ ).

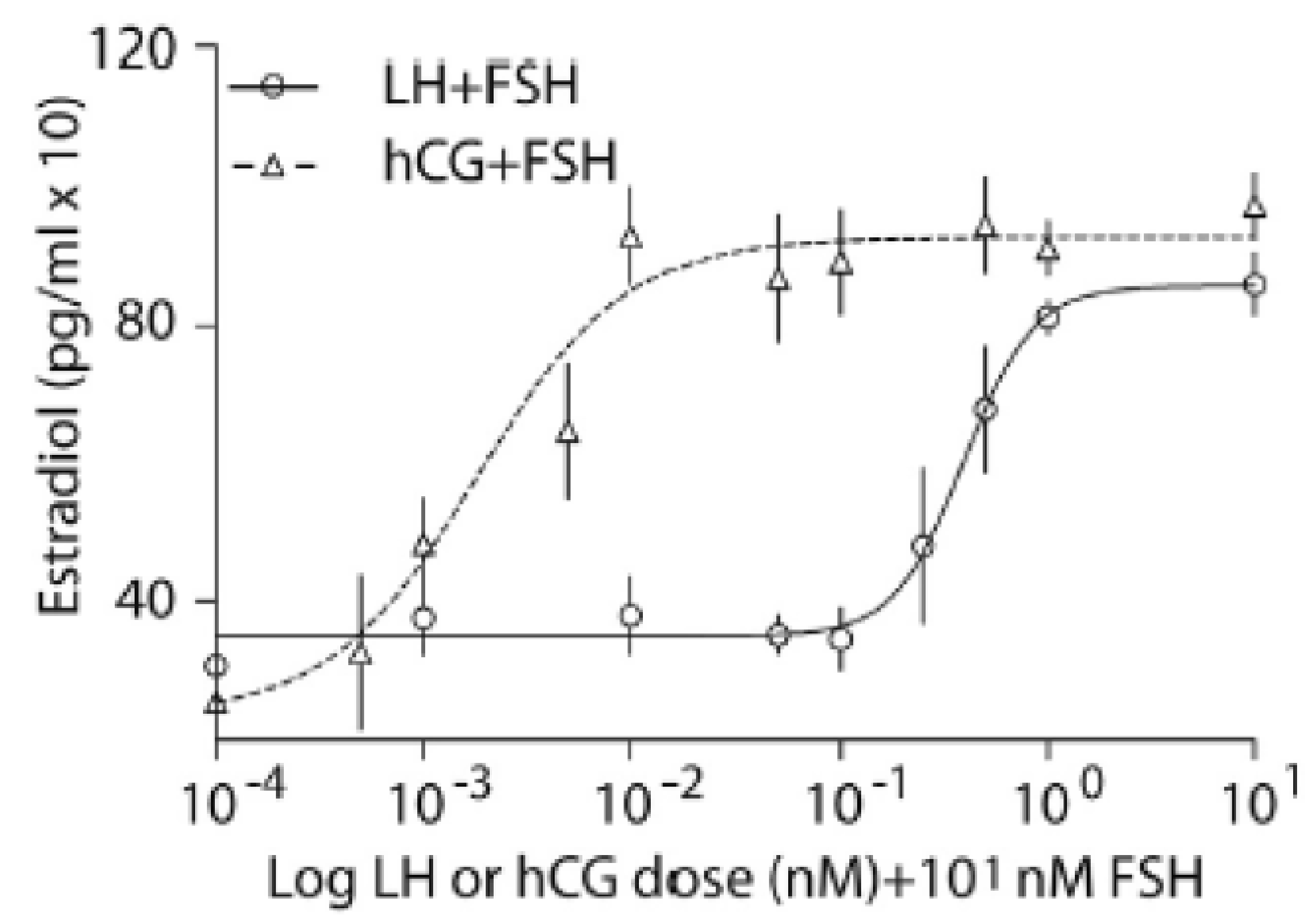

Figure 6. Evaluation of estradiol production. $\mathrm{hGLC}$ were stimulated $2 \mathrm{~h}$ by increasing LH or hCG doses, in the presence of $1 \times 10^{1} \mathrm{nM} F S H$, then they were washed twice with PBS and the estradiol was measured by ELISA after $24 \mathrm{~h} 1$ $\mathrm{MM}$ androstenedione was added to the cells media as substrate for the enzymatic conversion to estradiol. Estradiol levels were expressed as meanstSD $(\mathrm{pg} / \mathrm{ml})$ and non-linear regression calculated $(n=6)$. The EC50 $(\mathrm{LH}+\mathrm{FSH}=225.1 \pm 80.2$ vs $\mathrm{hCG}+\mathrm{FSH}=1.3 \pm 0.8 ; \quad \mathrm{p}=0.0022), \quad \mathrm{H}$-slopes $(\mathrm{LH}+\mathrm{FSH}=2.0 \pm 1.1$ vs $\mathrm{hCG}+\mathrm{FSH}=1.2 \pm 0.8 ; \mathrm{p}=0.4848)$ and maximal estradiol levels $(\mathrm{LH}+\mathrm{FSH}=921.1 \pm 86.6$ vs $\mathrm{hCG}+\mathrm{FSH}=954.5 \pm 39.5 ; \mathrm{p}=0.5887)$ were compared by ann-Whitney's U-test.

\section{ASEAM $\mid \begin{aligned} & \text { ASSOCIAZIONE SCIENTIFCA } \\ & \text { INENDCRNELLOGA } \\ & \text { ANDROLOGIAEMETABOLISMO }\end{aligned} \quad$ Contact information: livio.casarini@unimore.it www.endocrinologia.unimore.it}

